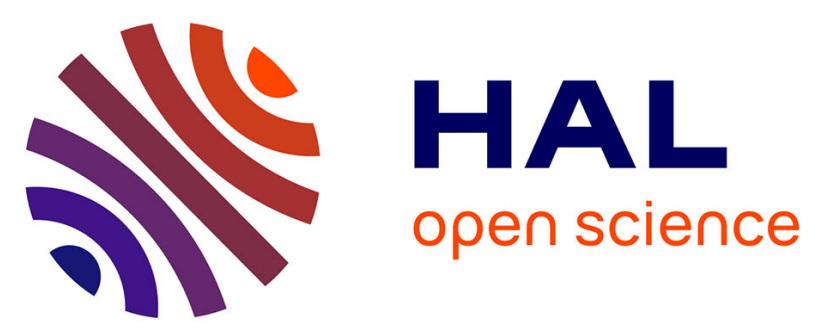

\title{
Conditions of possible head impacts for standing passengers in public transportation: an experimental study
}

Thomas Robert, Philippe Beillas, Alain Maupas, Jean-Pierre Verriest

\section{- To cite this version:}

Thomas Robert, Philippe Beillas, Alain Maupas, Jean-Pierre Verriest. Conditions of possible head impacts for standing passengers in public transportation: an experimental study. International Journal of Crashworthiness, 2007, 12 (2), pp. 1-9. 10.1080/13588260701433552 . hal-01862704

\author{
HAL Id: hal-01862704 \\ https://hal.science/hal-01862704
}

Submitted on 27 Aug 2018

HAL is a multi-disciplinary open access archive for the deposit and dissemination of scientific research documents, whether they are published or not. The documents may come from teaching and research institutions in France or abroad, or from public or private research centers.
L'archive ouverte pluridisciplinaire $\mathbf{H A L}$, est destinée au dépôt et à la diffusion de documents scientifiques de niveau recherche, publiés ou non, émanant des établissements d'enseignement et de recherche français ou étrangers, des laboratoires publics ou privés. 
5 Conditions of possible head impacts for standing passengers in public transportation: an experimental study.

ROBERT Thomas, BEILLAS Philippe, MAUPAS Alain, VERRIEST Jean-Pierre

10

Submitted to the International Journal of Crashworthiness

Number of words: 4200

15 


\section{Abstract}

Standing passenger safety is currently a major challenge for the development of public transportation. One of the current difficulties to overcome this problem is the lack of

5 knowledge about the motion of passengers following a minor incident, such as an emergency braking or a slight collision.

This study brings new experimental data about the head kinematics of volunteer subjects in situations representative of typical public transportation incidents. Two levels of perturbation were tested - representing an emergency braking and a minor collision - combined with 3

10 initial postures - free standing, using a back rest and holding a vertical bar. Data obtained were: 1/ the 3D head trajectories; 2/ the maximal excursions of the head along the longitudinal axis; $3 /$ Corridors of the head tangential velocity versus its longitudinal displacement.

Even though there are limitations, these data can be used as a first estimate to predict the risks of impact between the head of passengers and their surrounding environment. They also provide insight into the impact velocity of this eventual collision. Furthermore, they highlight the influence of the level of perturbation and of the restraint device possibly used.

These data are mainly intended to be used by designers of public transportation vehicles to improve the future interior layouts with regard to the standing passengers safety. 


\section{Introduction}

Passenger safety is currently a major challenge for the development of public transportation. One of the key issues is related to minor but frequent incidents. The injury data about 5 incidents without collision (e.g. emergency braking) in public transportation highlight this problem For example, the American Bureau of Transportation Statistics reported 8 deaths and 20967 persons injured in one year due to incidents without collision in urban and interurban buses in the United States [1]. Similarly, De Graaf and Van Weperen reported that from the 2300 persons brought to the Emergency Department following an incident in public transportation in one year in Netherlands, 1200 of them were injured in incident without collision [2].

Recent surveys on transport safety [3-5] have provided a better knowledge of the risks associated with this type of incident. These studies report that the most exposed passengers are the standing passengers: even slight incidents can induce important losses of balance,

15 which may lead to secondary impacts with other occupants or interior equipments, and thus cause injuries. These studies also report that the most injured segment is the head (between $23 \%$ and $33 \%$ of the injuries), followed by the upper limbs (between $20 \%$ and $28 \%$ ) and the lower limbs (between $18 \%$ and 21\%). Most of these injuries appear to be minor or moderate (within $85 \%$ and $98 \%$ of AIS $\leq 2$ ). However their social cost and their high frequency led the authors to judge that this situation is situation the most critical one [3].

Moreover, there are some aggravating factors: $1 /$ there will be more vulnerable passengers in the future because of the general ageing of the population and because of the increasing proportion of standing passengers in the new vehicle interior designs; $2 /$ the frequency of critical incidents should increase due to the apparition of new, complex, traffic situation (e.g. 
hybrid train-tram vehicles); $3 /$ this safety issue was widely neglected and starts only to be considered at its true value [5].

One possible solution to improve the safety of passengers would be to limit the 5 aggressiveness of vehicle interior designs. To achieve this, it would be crucial to be able to evaluate the risk of injuries associated with incident conditions (interior design, location and posture of the passengers, level of perturbation, etc). This would mean: $1 /$ to determine whether a impact may occur and against which structure; $2 /$ to determine the conditions of this impact (e.g. impact velocity); 3/ to estimate the injury risks associated with the impact.

10 Existing biomechanical data collected for other applications such as automotive safety or sport injury could be used to try to achieve this last point. However, one of the current difficulties is the determination of the impact conditions, and particularly the kinematics of the impacting segment (step 1 and 2). Although many studies about postural balance have been carried out (e.g. [6-11]), the configurations tested did not reflect the real situations encountered in public transportations. Therefore, there is currently a lack of pertinent data on the kinematics of standing human in situation that is representative of public transportation incidents.

As a first priority, it would be of interest to study the risks of impact for the head since: $1 /$ this segment is the most frequently injured; 2/ some of the arm injuries (the second most injured segment) can be explained by their use to protect the head [12-14].

In this study, 10 volunteer subjects were placed in situations representative of public transportation incidents (e.g. emergency braking and light collision). Their balance recovery was measured and analyzed in terms of $1 /$ head 3D trajectories; 2/ maximal head excursion; 3/ tangential velocity versus of head position corridors. These data can be used to help 
estimating: 1/ the risk of secondary impact with an element of the interior design; $2 /$ the impact velocity of this impact. They could be used by the designers to improve the future interior layouts with regard to the standing passenger safety.

\section{Test set-up}

The aim was to reproduce in the laboratory the situation of a standing passenger in a public transport vehicle submitted to a real-life incident (e.g. an emergency braking or a minor collision). Volunteer subjects were standing on a platform, initially immobile. The platform was connected to a sled by an elastic link and a cable. The sled was launched by a catapult, tightening the cable and applying a pulse to the platform (see Fig. 1 a). Because the link was elastic, the shape of the acceleration pulse was a half sinusoid.

\section{Experimental situations tested}

15 Two independent variables were investigated: $1 /$ the level of perturbation; $2 /$ the initial posture of the subjects, corresponding to the restraint device possibly used.

Two acceleration pulses, representing two levels of perturbation, were tested. Both had a duration of approximately $400 \mathrm{~ms}$ and a maximum acceleration of $2 \mathrm{~m} / \mathrm{s}^{2}$ or $10 \mathrm{~m} / \mathrm{s}^{2}$ (see Fig. $1 \mathrm{~b})$. Those were defined by the EC funded SAFETRAM project consortium as equivalent to an emergency braking situation and a low severity collision respectively. The perturbations were applied in the AP direction, with the platform moving towards their back.

Fig. 1 about here

Three initial postures were used by the volunteers: free standing with no device, holding a vertical bar, and resting their back against the back of a seat (see Figure 2). 
The volunteers were subjected to each possible combination of these two independent variables, resulting in six configurations per subject tested in a random order (see Table 1).

Table 1 about here

\section{Measurements}

Kinematics of balance recovery was recorded using a Motion Analysis ${ }^{\circledR}$ opto-electronic system. Fifty reflective markers $(25 \mathrm{~mm}$ spheres) were placed on specific external points of the volunteers. Five red light cameras, with a sampling frequency of $200 \mathrm{~Hz}$, measured their 3D trajectories during the movement.

\section{Population}

For this first study, only one homogeneous group of population was investigated. It was composed of ten young male subjects (mean: 25.6 years old, s.d.: 2.4), with an average stature (mean: $176.8 \mathrm{~cm}$, s.d.: 3.1 ) and mass (mean: $72.6 \mathrm{~kg}$, s.d.: 4.8). They were recruited outside

15 the institute and were thus naïve to the experiments. They were submitted to a preliminary medical examination to ensure that they never had equilibrium troubles or any medical interventions on the lower limbs.

\section{Instructions and surprise effect}

20 For each test, volunteers were asked to stand relaxed on the platform, as if they were on board of a public transport. They were only instructed to use the available devices (vertical bar or bump rest).

Although the subjects knew that a longitudinal perturbation would occur, measures were taken in order to observe the most natural responses possible. Volunteers could not see the moving sled starting, and a headphone insulated them from the sounds of the laboratory. As 
the test order was randomized, they could not anticipate the beginning and nor the magnitude of the pulse. Furthermore, an operator asked them a succession of short questions (such as arithmetic calculations or words spelling) via the headphone, in order to distract their mind from the balance recovery.

\section{Safety of the subjects}

In order to prevent any fall or impact with the environment, subjects wore a harness linked to a beam fixed to the platform above them. This device did not interfere with the balance recovery movements.

10 This protocol complied with the terms of the law on biomedical experiments with human living subjects and was approved by the regional ethical committee.

\section{Data processing}

\section{Movement reconstruction}

Balance recovery movements were reproduced on the numerical dummy Man3D developed in the laboratory [15]. The kinematic model of this dummy was simplified to 15 segment linked by joints (40 degrees of freedom), and its dimensions were fitted to each subject anthropometry. Then an optimization method was applied at each frame of the movement to

20 find the set of joint angles (i.e. dummy posture) that best fitted the subject measured position [15]-[16].

Joint angles were filtered using Butterworth $2^{\text {nd }}$ order zero lag filters. Cut-off frequencies were adjusted for each degree of freedom using the residual analysis method [17]-[18]. This resulted in cut-off frequencies between $7 \mathrm{~Hz}$ and $20 \mathrm{~Hz}$, depending on the motion and the degree of freedom. 
The accuracy of this method has been evaluated [16]: the average distance between the measured positions of the markers and their corresponding points on the virtual dummy was less than $27 \mathrm{~mm}$, which is negligible compared to the amplitudes of the studied motions.

\section{Time range of the motions}

The time origin was chosen at the onset of the platform motion. The end was defined at the time when the longitudinal velocity of the head (along $\mathrm{X}$ axis) equalled zero. However, the translation of the platform relative to the optoelectronic system induced measurement difficulties, such as loss of markers at the end of the movement. Therefore, some trials could not be reconstructed for the total duration of the movements (see Table 2). These missing parts are near the end of the movement, therefore corresponding to small displacements and low velocities. In those cases, the missing kinematics of the head CoM for the end of the movement was estimated based on the use of raw head markers positions or the trend of the displacement curves. The average correction of the displacement at the end of the motion was at most $14 \%$ of the total head displacement along the $\mathrm{X}$-axis (case of the experimental situation \#4).

\section{D head kinematics}

The head was represented by its Centre of Mass (CoM). As a first approximation, this point was considered to be the cranio-cervical joint centre, which is the closest dummy's point (point teco). The distance between these two points (teco and CoM) was estimated to be around $40 \mathrm{~mm}$, which is small compared to the amplitude of the motion. Moreover, it was verified that this assumption had a negligible influence on the computed head velocity. 
For each frame, the CoM coordinates in the reference frame of the platform was computed using the reconstructed data. In order to compare the 3D head trajectories for the different trials, the CoM coordinates were set to zero at the onset of the platform.

Velocities of the head relative to the reference frame of the platform were computed along the

5 three axes by differentiating the head CoM coordinates. The tangential velocity $V_{t}$ was then computed as the norm along the 3 axis of these velocity vectors.

\section{Response corridors for the head tangential velocity}

In order to represent the variability in the subject reactions in each of the six configurations,

10 response corridors of the head tangential velocity as a function of the head location were built as follows.

The head tangential velocity (ordinate) was computed as a function of the head location (abscissa) along one of the 3 reference axes. All velocity data were then interpolated on a common, equally spaced, abscissa vector (one point every $1 \mathrm{~mm}$ ). The mean and standard deviation of the tangential velocity of the head were calculated at each point of this common vector. Corridors boundaries were defined as the mean head tangential velocity plus or minus one standard deviation.

The length of the common abscissa vector was defined by the movement with the maximal head excursion. If a movement ended normally (head velocity along X-axis equals zero), its velocity was assumed to remain equal to zero after this point. If a movement ended because it was not fully reconstructed (see Time range of the motions above), it was not considered anymore after this point and the mean and standard deviation were calculated using the remaining movements. 


\section{Results}

\section{Head trajectories}

3D head trajectories were plotted for each experimental conditions and every subject (Figure 3). Three positions of the whole body model were superimposed in order to illustrate the

5 whole body kinematics of the balance recovery (first, intermediate and last frame of a typical subject).

Fig. 3 about here

This figure shows that the balance recovery kinematics and the head trajectories varied widely with the experimental situation. The low level of perturbation, while using a back rest, induced only a really small motion of the top of the body. Besides, although none of the subject fell on the ground, the highest level of perturbation induced a very important disequilibrium for the free standing posture.

The head of the subjects moved mainly along the $\mathrm{X}$-axis (longitudinal axis). This was verified even for the asymmetric situations where the subject grasped the bar: for the experimental

situation number 6 (high perturbation, grasping a bar) the maximal excursion along the $\mathrm{Y}$-axis averaged for every subjects was only $17,4 \mathrm{~cm}$ - approximately the same as for the Z-axis $(15,8$ $\mathrm{cm}$ ) - while this value was $96,6 \mathrm{~cm}$ along the $\mathrm{X}$-axis. Consequently, in the rest of this paper, head kinematics is only investigated along the longitudinal axis (X-axis).

\section{Maximal excursion of the head}

The maximal excursion of the head was defined as the maximal X-coordinate of the head CoM during the movement.

Results are displayed in Table 2. They highlight the differences of motion amplitude depending on the experimental situation: The head excursions were lower than $150 \mathrm{~mm}$ for the experimental situation \#3 (use of a back rest, low level of perturbation), while they were 
higher than $1500 \mathrm{~mm}$ for the experimental situation \#2 (free standing, high level of perturbation).

The use of a restraint device limited this excursion of the head. At low level of perturbation, the back rest was extremely efficient. However, at higher level of perturbation, the opposite

5 was observed: gripping a vertical bar limits more the head longitudinal displacement than using a back rest.

Table 2 about here

\section{Alternative strategies}

10 Subjects could adopt different strategies to restore their balance, as already described in a detailed analysis of the whole body kinematics ([16], [19]). Therefore, presence of alternative strategies was investigated on the basis of the maximal excursions of the head.

For each experimental situation, bar charts of the maximal head excursion were plotted (see Fig. 4). From these graphs, two different strategies (main strategy and alternate strategy) can be identified for the experimental situation 1 and 5 (low level of perturbation, free standing and grasping a vertical bar respectively). The meaning of these strategies will be discussed in the next section of this paper.

Fig. 4 about here.

\section{Head velocity}

Figure 5 represents the head tangential velocities (corridors and averages) as a function of its longitudinal displacement for the main strategy of each experimental situation.

Fig. 5 about here. 
It is important to notice the difference of amplitude, both for $\mathrm{X}$ and $\mathrm{V}_{\mathrm{t}}$, between the corridors corresponding to the low and high level of perturbation: 100 to $2500 \mathrm{~mm}$ for the maximal head excursion, and from 300 to $2500 \mathrm{~mm} / \mathrm{s}$ for the maximal head velocity.

The effect of the restraint devices was negligible at the beginning of the motion: corridors are nearly superimposed during the first $30 \mathrm{~mm}$ or $300 \mathrm{~mm}$ for the situations at low or high level of perturbation respectively. It can be noticed that although these common parts of the motions represents only almost $10 \%$ of the maximal head excursion, the tangential head velocities reached in this area from 30\% (free standing - low perturbation) to 100\% (back rest - high perturbation) of its maxima.

10 However, the use of a restraint device allowed limiting both the maximal head excursion and the maximal head tangential velocity. This influence was dependant of the level of perturbation, mainly for the head velocity. Indeed, the capacity of a device to limit the maximal head velocity decreased when the level of perturbation increased: at low level of perturbation, the maximal head velocity was divided by almost 2 or 2.5 using a vertical bar or

15 a back rest respectively, while at high level of perturbation these factors were only within 1.2 and 1.7 (vertical bar or a back rest respectively).

\section{Discussion}

Influence of the restraint devices

20 The analysis suggested that the two restraint devices tested (vertical bar and back rest) acted differently. This can be seen on the head velocity versus head displacement curves. The use of the back rest limited the duration of the first part of the curves - that corresponds to the speed increase - without affecting the overall shape of the curves. On the opposite, the vertical bar affected mainly the second part of the curves: it increased the slope of this descending part, thus limiting the head excursion. A schematic illustration of this effect is provided on Fig. 6 . 
Fig. 6 about here.

One possible explanation for this behaviour, and that is in accordance with the proposed interpretation of the feeling of disequilibrium indicated by the subjects [20], is the following: 1/ The use of a back rest increase the steadiness of the initial posture, and thus limits the 5 disequilibrium. However, it does not help the subject to restore their balance once the disequilibrium is induced.

2/ Grasping a vertical bar does not limit the initial disequilibrium, as it does not modify significantly the initial steadiness of the standing posture. However, it offers the possibility to restore the balance after the start of the fall forward.

\section{Meaning of the alternative strategies}

For two experimental situations (free standing and grasping a vertical bar, low level of perturbation), alternative strategies were observed (see Table 3). These alternative strategies may be due to the low level of constraints imposed on the subject responses. Purposefully,

few instructions were given to the subjects in order to observe the diversity of individual responses. Since the disequilibrium induced by the low level of perturbation was small, it may not have been sufficient to force the subjects to use the most efficient strategy to restore their balance. This was obvious in the experimental situation \#1 (free standing - low level of perturbation): while most subjects tried to restore their balance as fast as possible, three subjects took advantage of the space available in front of them and "let themselves walk" (see Fig. 7). Thus, their movement was characterized by a higher distance to restore their balance and a lower head tangential velocity.

Similarly, for the experimental situation \#5, all subjects were gripping the vertical bar and most of them used it to shorten their recovery motion. However, 3 of the subjects did not: their head motions were similar to those observed in the main strategy ( 2 of the 3 subjects) or 
the alternative strategy ( 1 of the 3 subject) of the experimental situation \#1. This is illustrated by the head tangential velocity versus its X-coordinate curves on Fig. 7.

Fig. 7 about here

When submitted to the higher level of perturbation, subjects had to use the most efficient strategies to avoid falling. As a consequence, the dispersion of maximal excursions of the head was lower for trials at high level of perturbation, and no real alternative strategies could be observed.

The reason why certain subjects chose alternative strategies is uncertain. One possibility is that the choice of an alternative strategy was done voluntarily by the subjects, in order to restore their balance in an easier way than the main (most efficient) strategy.

If such a voluntary choice is possible, we could suppose that, in presence of an obstacle in front of them, subjects would adopt the most efficient strategy (here presented as the main strategy) to avoid the risk of impact. This is however only a working hypothesis and the influence of obstacles on the balance recovery motion should be studied separately.

\section{Risks and conditions of secondary impacts}

Predicting of the risk and condition of impact between subjects and their environment using the experimental data presented in this paper requires to make an hypothesis: the presence of an obstacle on the trajectory of the subjects would not have modified their balance recovery

kinematics, measured here in an open space.

At first, this appears like a strong assumption. However, the analysis of the strategies indicated that, for the main strategies, subjects may have tried to restore their balance in the most efficient way possible. If the subjects were already near their maximum level of performance, then it is likely that the balance recovery kinematics would be only slightly 
modified by an attempt of obstacle avoidance. The potential use of the upper limbs would however have to be investigated.

Overall, although further studies should focus on those points, the assumption may be reasonable for those preliminary results. Furthermore, even if the passengers would manage to

5 modify significantly their balance recovery kinematics, the prediction could be considered to be a conservative measure in the process of estimating the risk of impact. Therefore, it appears reasonable to use the corridors of the head tangential velocity function of its location presented in Fig. 5 as insights to estimate the risks and conditions of a potential head impact. Caution should be used when using the results towards the end of the movement (free standing situation in particular) because of: $1 /$ the limited number of subjects still in motion and $2 /$ the fact that they are less constrained by the perturbation since they have almost completely restored their balance.

It can be observed that head excursions were large mainly at high level of perturbation: between 1 and 2 meters (see Table 2). Related to the lack of space available in the interior of a 15 public transportation vehicle, these distances suggest a high risk of secondary impacts. Moreover, the head tangential velocities were quite large for the higher level of perturbation: they reached up to $3 \mathrm{~m} / \mathrm{s}$ in free standing posture. These are of the same order as the secondary impact velocity experimentally observed for seated inert dummies in a train crash situation (between 4 and $7 \mathrm{~m} / \mathrm{s}$ in a crash of a train, running at $110 \mathrm{~km} / \mathrm{h}$, against a 15 tons truck stopped on the railway at a crossing [21-22]). Moreover, the maximal head velocities happened relatively far from the initial position (up to $60 \mathrm{~cm}$ for the experimental situation \#2), which means in zones likely to be impacted.

It can also be remarked that in every cases the use of a restraint device limited the risk of head impact and the potential velocities of these impacts. However, if they seemed really effective at low level of perturbation, they may not be sufficient to protect passengers at high level of 
perturbation. This is illustrated by the fact that, at high level of perturbation, the head velocity was higher than $1 \mathrm{~m} / \mathrm{s}$ nearly 1 meter away from its initial location, even using a restraint device.

\section{Limitations and perspectives}

One of the main limitations of this study concerns the potential influence of obstacles on head motions. Even if indications, such as the analysis of the alternatives strategies, suggest, for the levels of perturbation considered, this influence is limited, future studies should focus on this point.

10 Moreover, as a first study, the aim was not to be exhaustive. More data should be data collected. Other directions of perturbation should be tested for example. Another point concerns the group of population tested. Young males that performed these experiments did not represent the most critical group of population. It would have been more interesting to study the reactions of elderly or disabled persons. However, due to evident safety problems, this is not experimentally possible. Therefore, a future objective would be to model the balance recovery, based on experimental data collected with young and healthy subjects. These models could then be modified to fits with other groups of population.

\section{Conclusions}

20 This study brings new experimental data about the head kinematics of volunteer subjects in situations representative of typical public transportation incidents. Two level of perturbation were tested - representing an emergency braking and a minor collision - combined with 3 initial postures - free standing, using a back rest and gripping a vertical bar. Data obtained were: 1/ the 3D head trajectories; $2 /$ the maximal excursions of the head along the 
longitudinal axis; 3/ Corridors of the head tangential velocity versus its longitudinal displacement.

Even though there are limitations, these data can be used as a first estimate to predict the risks of secondary impact between the head of passengers and their surrounding environment. They

5 also provide insight into the impact velocity of this eventual collision. Furthermore, they highlight the influence of the level of perturbation and of the restraint device possibly used.

These data are mainly intended to be used by designers of public transportation vehicles to improve the future interior layouts with regard to the standing passenger safety.

\section{Acknowledgement}

These experiments were conducted within the frame of the EC funded SAFETRAM project, in collaboration with the French railways company (SNCF). The authors which to thank the persons who voluntarily agreed to be subjects of these experiments. 


\section{References}

[1] BTS | Table 2-15: U.S. Transit Safety Data: 2000 [on line]. Available on: $<$ http://www.bts.gov/publications/state_transportation_profiles/nebraska/html/table_02_ $\underline{15 . h t m l}>$

[2] B. de Graaf, W. van Weperen. The retention of balance: an exploratory study into the limits of acceleration the human body can withstand without losing equilibrium. Hum. Factors. 1997, 30, 111-118.

10 [3] M. S. Pereira, M. Hecht, V. Segurado, S. Sohr, M. Uettwiller, LRV STATISTICS, Passive Safety in Urban Railway Systems, Light Rail Vehicle (LRV) - Accident Statistics, Final report, Safetram project, May 2001, 94 pp. Available online: $\langle$ http://www.eurailsafe.net/projects.php?id=85>

[4] U. Björnstig, P. Albertsson, J. Björnstig, P.-O. Bylund, T. Falkmer, J. Petzäll, Injury Events Among Bus And Coach Occupants - Non-crash Injuries as Important as Crash Injuries, IATSS Research, 2005, 29, 79-87.

[5] P. Halpern, M. I. Siebzehner, D. Aladgem, P. Sorkine and R. Bechar, Non-collision injuries in public buses: a national survey of a neglected problem, Emerg. Med. J., 2005, 22, 108-110.

[6] M.C. Do, Y. Breniere, P. Brenguier, A biomechanical study of the balance recovery during the fall forward. Journal of Biomechanics, 1982, 15, 933-939.

[7] B.E. Maki, W.E. McIlroy, S.D. Perry, Influence of lateral destabilization on compensatory stepping responses. Journal of Biomechanics, 1996, 29, 343-353.

[8] Y.C.Pai, J. Patton, Center of mass velocity-position predictions for balance control. Journal of Biomechanics, 1997, 30, 347-354.

[9] C.F. Runge, C.L. Shupert, F.B. Horak, F.E. Zajac, Ankle and hip postural strategies defined by joint torques. Gait and Posture, 10, 161-170.

[10] E.T. Hsiao, S.N. Robinovitch, Biomechanical influences on balance recovery by stepping. Journal of Biomechanics, 1999, 32, 1099-1106.

[11] S.M. Henry, J. Fung, F.B. Horak, Effect of stance width on multidirectional postural responses. Journal of Neurophysiology, 2001, 85, 559-70.

[12] W.E McIlroy, B.E. Maki, Compensatory arm movements evoked by transient perturbations of upright stance. In Tagushi K., Igarashi M., Mori S., eds. Vestibular and Neural Front., Amsterdam, The Netherlands : Elsevier Science Publishers BV. 1994, pp. 489-492.

[13] B.E. Maki, W.E. McIlroy W.E. The role of limb movements in maintaining upright stance: the "change in support" strategy. Physical Therapy, 1997, 77, 488-507. 
[14] K.J. Kim, J.A. Ashton-Miller, Biomechanics of fall arrest using the upper extremity: age differences. Clinical Biomechanics, 2003, 18, 311-318.

[15] J.-P. Verriest, Simulation of human movement for ergonomic design on numerical mock-up. Transportation Research Record, 1998, 1631, 8-12.

[16] T. Robert, Analyse biomécanique du maintien de l'équilibre debout suite à une accélération transitoire de la surface d'appui - Application à l'amélioration de la protection des passagers debout de transport en commun. $\mathrm{PhD}$. thesis in Biomechanics, National Institute of Applied Sciences, Lyon, 2006.

[17] D.A. Winter, Biomechanics and motor control of human movement. John Wiley \& Sons, New York, 1990.

[18] M. Silva, J. Ambrósio, Human motion analysis using multibody dynamics and optimization tools, Technical Report IDMEC/CPM - 2004/001, Instituto de Engenharia Mecanica, Lisboa, 2004.

[19] T. Robert, M. Fayet, D. Leveque, J.-P. Verriest, Kinematic modelling of balance recovery movements of a standing passenger following its support surface translation, presented at the S.A.E Digital Human Modeling for Design and Engineering Conference, 4-6 July, Lyon (France), 2006.

[20] T. Robert, Experimental study of the balance control of standing passengers in public transport, In: Contemporary Ergonomics 2005, Philip D Bust and Paul T McCabe (Eds), pp. 432-436, Taylor and Francis.

[21] J.W. Simons, S.W. Kirkpatrick, High-Speed Passenger Train Crashworthiness and Occupant Survivability, IJCrash, 1999, 4, 216-226.

[22] D. C. Tyrell, K. J. Severson, and B. P. Marquis, Train Crashworthiness Design for Occupant Survivability, presented at the Applied Mechanics Division of ASME Winter Annual Meeting, in San Francisco, California, November 12-17, 1995. 

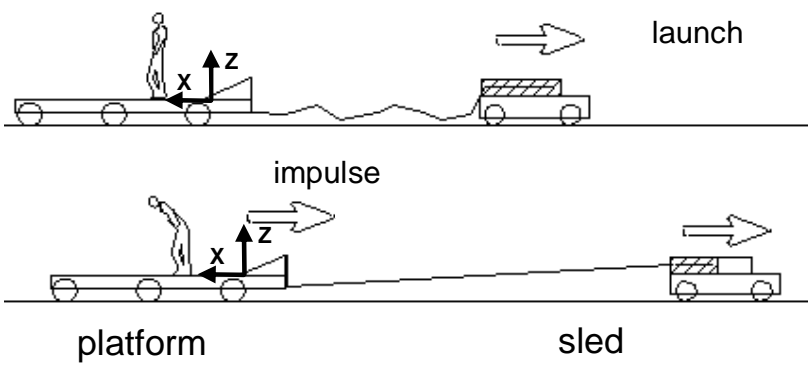

a/ Testing principle

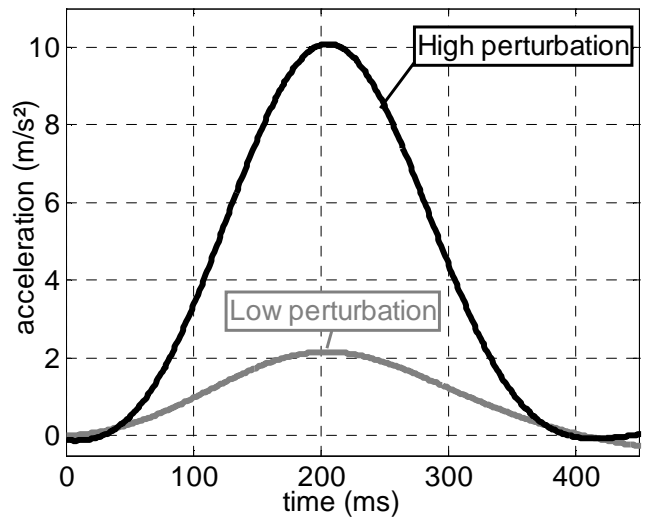

b/ Characteristics of perturbation

Figure 1: Experimental setup
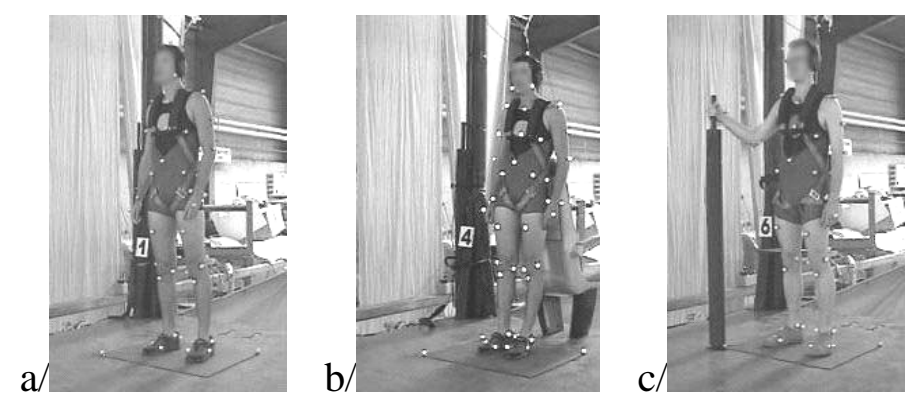

5 Figure 2: Initial postures: a/ free standing; b/ using a back rest; c/ holding a vertical bar. 


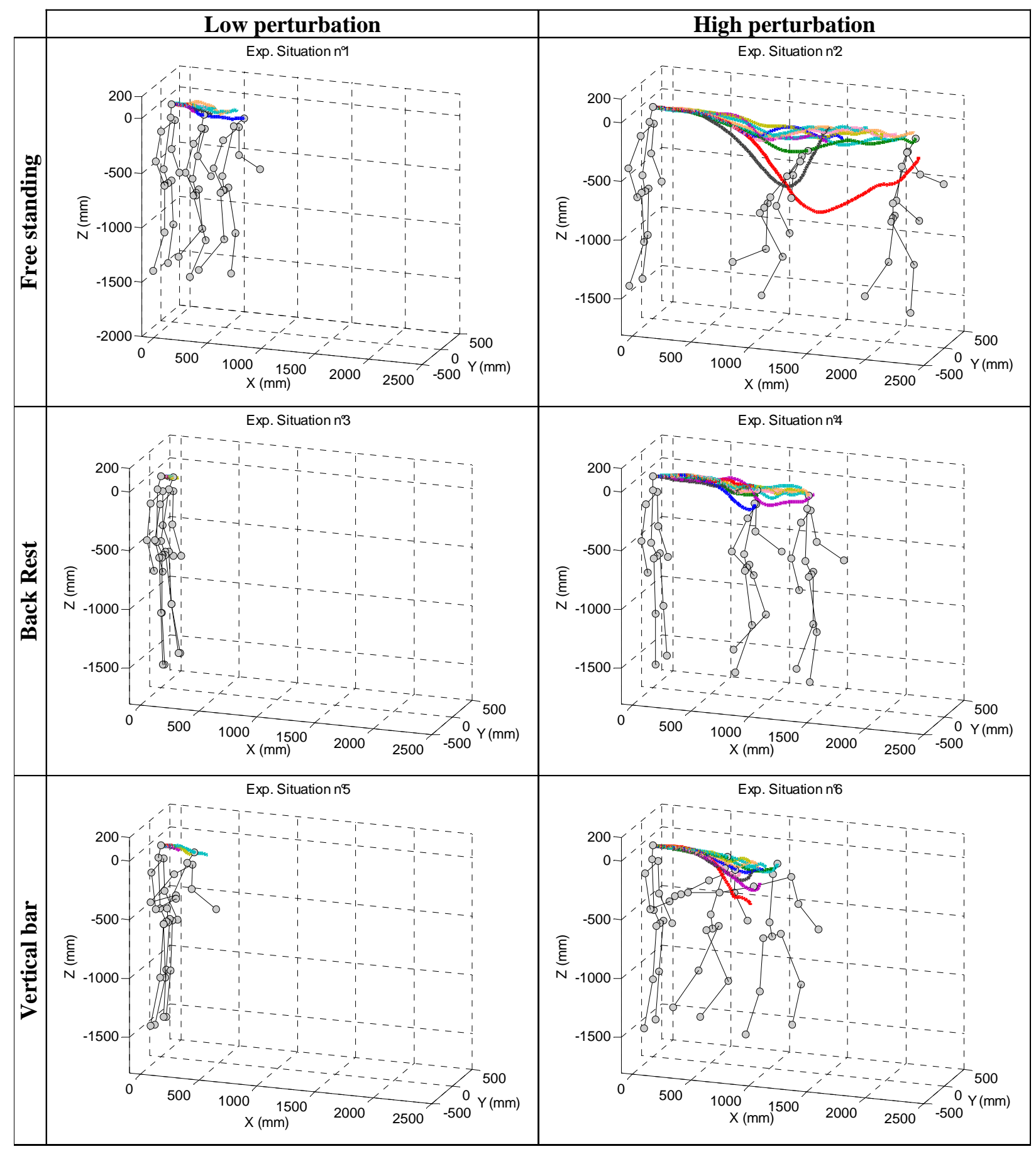

Figure 3: 3D head trajectories of the subjects for the 6 experimental situations. For each graph, 3 reconstructed postures (first frame, intermediate and last frame) of one of the subjects are plotted. Notice the difference of amplitude depending on the experimental situation. 


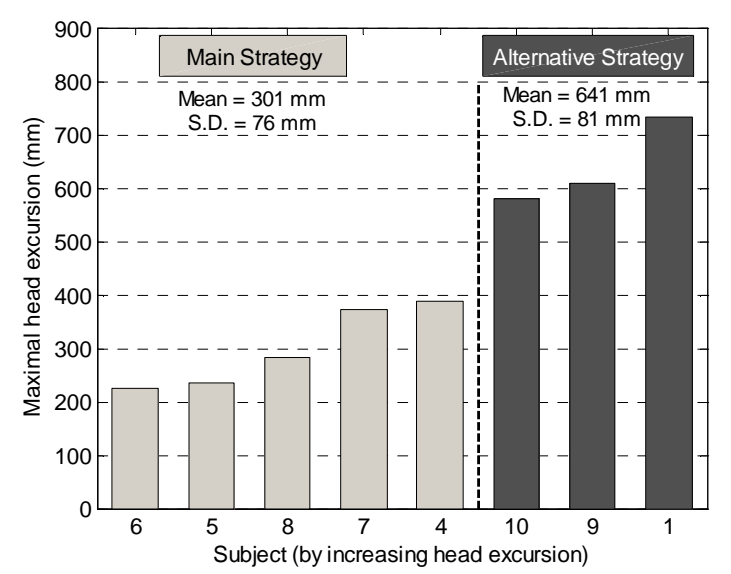

a/ Experimental situation \#1

(free standing - low level of perturbation)

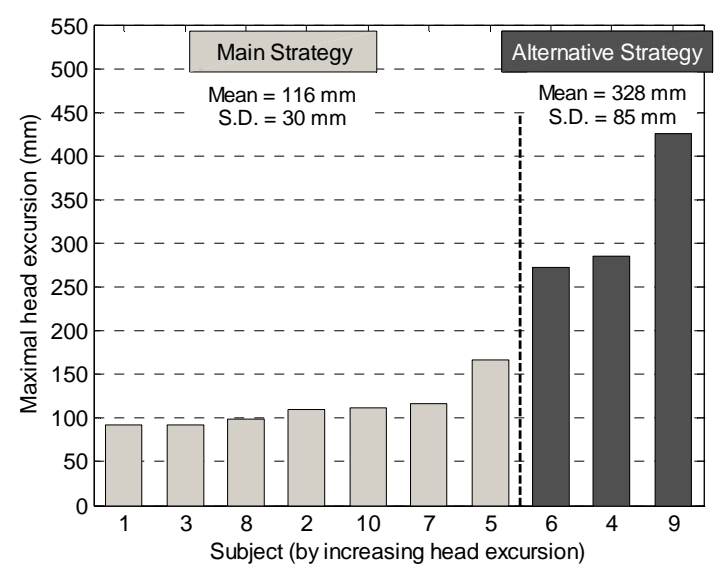

b/ Experimental situation \#5 (vertical bar - low level of perturbation)

Figure 4: Maximal head excursions along the $\mathrm{X}$-axis. Two strategies (main and alternative) can be identified for these two experimental situations.

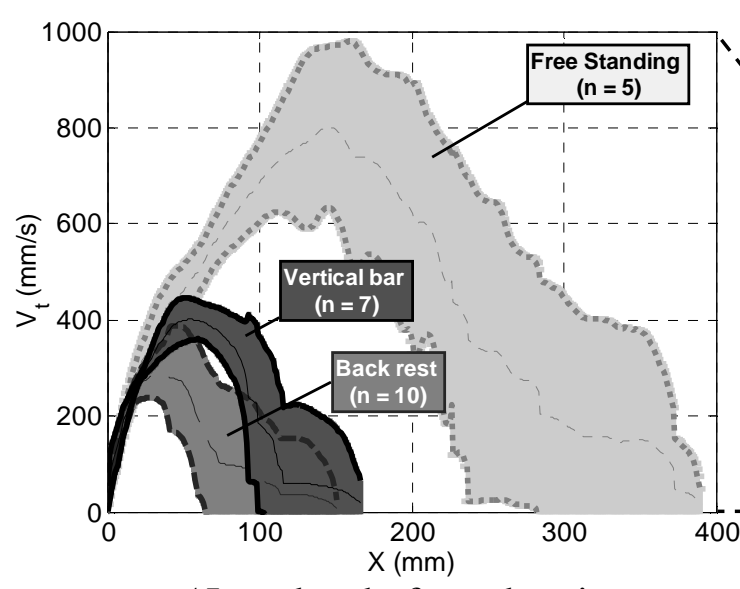

$\mathrm{a} /$ Low level of acceleration

(half sinusoid-duration $400 \mathrm{~ms}$-accel $\max 2 \mathrm{~m} / \mathrm{s}^{2}$ )

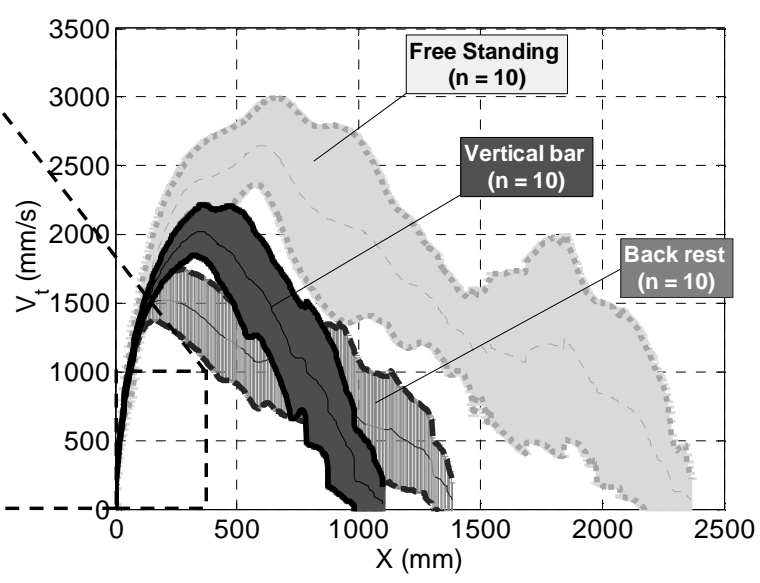

$\mathrm{b} /$ High level of perturbation

(half sinusoid-duration $400 \mathrm{~ms}$-accel $\max 10 \mathrm{~m} / \mathrm{s}^{2}$ )

Figure 5: Experimental Corridors for the head tangential velocity as a function of its Xcoordinate, for the 6 tested configurations. Notice the differences of scales for $\mathrm{X}$ and $\mathrm{V}_{\mathrm{t}}$ between the two graphs. 


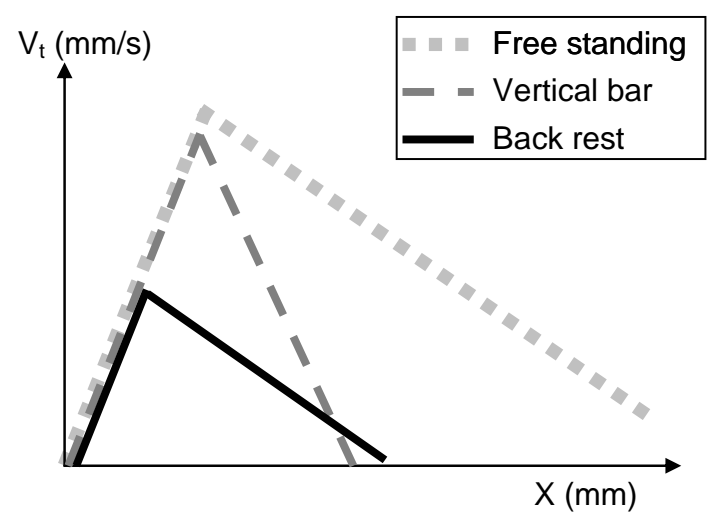

Figure 6: Schematic representation of the head velocity against its X-displacements for 3 conditions of support.

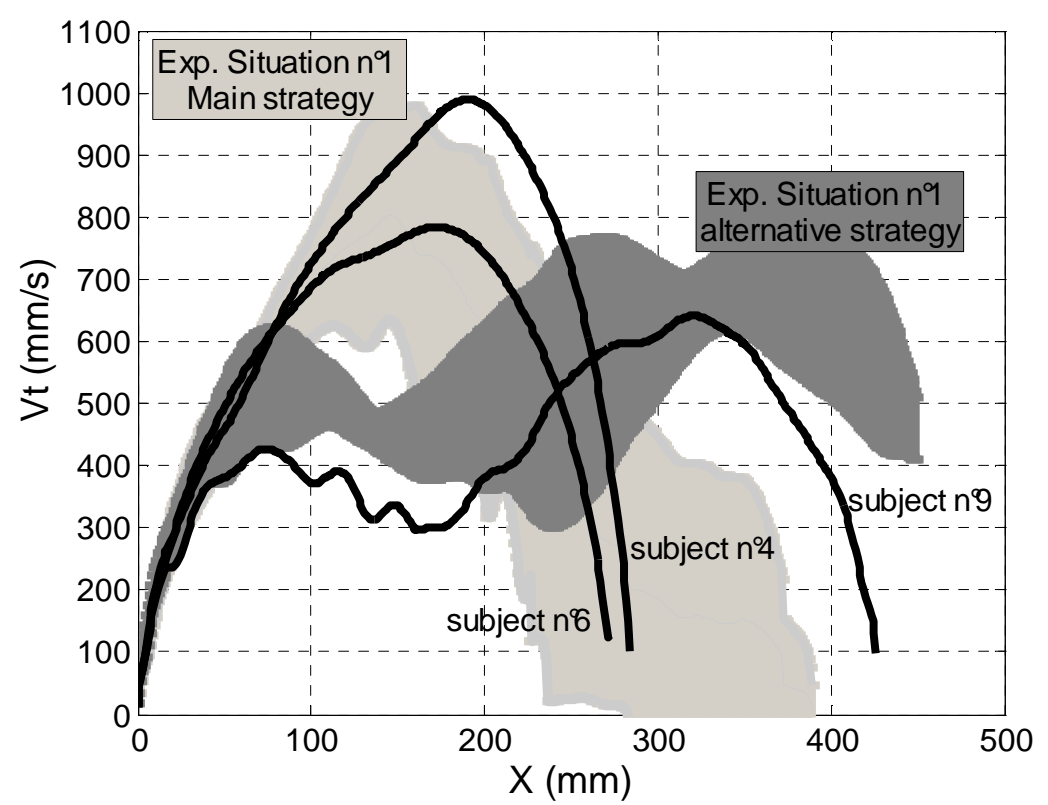

Figure 7: Head velocity against its X-displacements for the 3 subjects of the alternative strategy for experimental situation \#5 (vertical bar - low perturbation). On the background are plotted the corridors for the main and alternative strategy (light grey area and dark grey area respectively) of the experimental situation \#1 (free standing - low perturbation). Notice that alternative reactions to the experimental situation \#5 correspond to the reaction to the experimental situation \#1. 


\begin{tabular}{lll} 
situations & restraint device & $\begin{array}{l}\text { level of } \\
\text { perturbation }\end{array}$ \\
\hline 1 & $\varnothing$ & low \\
2 & $\varnothing$ & HIGH \\
3 & back rest & low \\
4 & back rest & HIGH \\
5 & vertical bar & low \\
6 & vertical bar & HIGH \\
\hline \multicolumn{2}{l}{ Table $1:$ test matrix for the first series }
\end{tabular}

Table 1: test matrix for the first series

\begin{tabular}{lrlllll} 
& \multicolumn{6}{c}{ Experimental situation } \\
\cline { 2 - 7 } subjects & 1 & 2 & 3 & 4 & 5 & 6 \\
\hline 1 & $733^{*}$ & $1752^{*}$ & 40 & 930 & 93 & 985 \\
2 & $\varnothing$ & $2281^{*}$ & 67 & $968^{*}$ & 110 & 1060 \\
3 & $177^{*}$ & 2397 & 58 & $1045^{*}$ & 93 & 982 \\
4 & 389 & 2370 & 113 & $1950^{*}$ & 285 & 1102 \\
5 & 236 & $1614^{*}$ & 63 & $1399^{*}$ & 167 & 980 \\
6 & 226 & 1977 & 151 & $2250^{*}$ & 272 & 865 \\
7 & 372 & 1542 & 72 & 851 & 116 & 875 \\
8 & 283 & $2524^{*}$ & 58 & $1392^{*}$ & 99 & 784 \\
9 & $609^{*}$ & $1924^{*}$ & 73 & $1694^{*}$ & 426 & 1042 \\
10 & $581^{*}$ & 2220 & 101 & $1383^{*}$ & 111 & 988 \\
\hline mean & $\mathbf{4 0 1}$ & $\mathbf{2 0 6 0}$ & $\mathbf{8 0}$ & $\mathbf{1 3 8 6}$ & $\mathbf{1 7 7}$ & $\mathbf{9 6 6}$ \\
S.D. & 196 & 348 & 33 & 465 & 113 & 98 \\
\hline
\end{tabular}

Table 2: Maximal excursions of the head (mm). 